\title{
AVALIAÇÃO DE FARINHAS DE TRIGOS CULTIVADOS NO RIO GRANDE DO SUL NA PRODUÇÃO DE BISCOITOS ${ }^{1}$
}

\author{
Luiz Carlos GUTKOSKI ${ }^{2, *}$, Mariana Lenzi NODARI ${ }^{3}$, Raul JACOBSEN NETO ${ }^{4}$
}

\section{RESUMO}

$\mathrm{Na}$ indústria de biscoitos é fundamental a definição de parâmetros para selecionar o uso do trigo em estudo. Existe uma série de testes químicos, físicos, enzimáticos e funcionais que podem caracterizar a qualidade tecnológica da farinha. Com o presente trabalho objetivou-se estudar diferentes cultivares de trigo cultivados no Estado do Rio Grande do Sul para a produção de biscoitos tipo semi-duros através de análises físicas, químicas, reológicas e funcionais. Grãos de trigo de amostras dos cultivares BR 23, BRS 120, BRS 49, BRS 177, BRS 119, BRS 176, PF 940097 e EMBRAPA 40 foram condicionados para 15\% de umidade, moídos em moinho piloto Chopin e analisados. As determinações realizadas foram peso de mil grãos, dureza do grão, peso do hectolitro, moagem experimental, composição química, número de queda e alveografia. Os biscoitos foram elaborados de acordo com método da AACC e avaliado volume específico, diâmetro, espessura, fator de expansão e cor. A metodologia utilizada no laboratório para a elaboração de biscoitos tipo semi-duros é adequada para a avaliação de uso final de farinhas de trigo. Com base nas propriedades funcionais, as farinhas de trigo dos cultivares BR 23 , BRS 120 e BRS 176 foram as mais recomendadas para a produção de biscoitos.

Palavras-chave: trigo; proteinas; dureza; reologia; biscoito.

\section{SUMMARY}

EVALUATION OF WHEAT FLOUR CULTIVATED IN THE RIO GRANDE DO SUL TO PRODUCTION OF BISCUITS. In the biscuit industry the definition of parameters to select the use of the wheat in study is basic. A series of chemical, physical, enzymatic and functional tests exists which can characterize the technological quality of the flour. The purpose of this research was to study cultivates of wheat cultivated in the state of the Rio Grande do Sul in the production of biscuits through physical, chemical, rheological and functional analysis. Samples of wheat cultivates BR 23, BRS 120, BRS 49, BRS 177, BRS 119, BRS 176,940097 PF and EMBRAPA 40 were conditioned for $15 \%$ of moisture content and milling in mill pilot Chopin. With the milling samples it was determined the weight of a thousand grains, kernel hardness, hectoliter weight, experimental milling, chemical composition, falling number and alveogram values (work W). The biscuits had been elaborated in accordance with the AACC and it was evaluated specific volume, diameter, thickness, spread factor and color. The methodology used in the laboratory in the production of the sugar-snap cookie type is adjusted for the evaluation of wheat final flour use. On the basis of the functional properties, the flour of cultivates of wheat BR 23 , BRS 120 and BRS 176 were recommended for the biscuit production.

Keywords: wheat; protein; hardness; rheology; cookie.

\section{1 - INTRODUÇÃO}

A qualidade de grãos e farinhas de trigo é determinada por uma variedade de caracteristicas que assumem diferentes significados dependendo da designação de uso ou tipo de produto. Estas características podem ser classificadas em fisicas, químicas, enzimáticas e funcionais $[19,23]$.

Segundo RAO \& RAO [22] a avaliação reológica da farinha é de vital importância para a indústria de panificação ajudando a predizer as características de processamento da massa e a qualidade dos produtos finais. A reologia também desempenha importante papel no controle de qualidade e na definição da especificação de ingredientes dos produtos elaborados. Entre as determinações disponiveis para avaliar objetivamente as propriedades da massa e definir o uso final da farinha de trigo na panificação, incluem-se as de características de

1. Recebido para publicação em 05/04/2002. Aceito para publicação em 10/09/2003 (000827).

2 Faculdade de Agronomia e Medicina Veterinária da Universidade de Passo Fundo. Caixa postal 611, CEP 99001-970, Passo Fundo, RS. Email:gutkoski@upf.tche.br. Bolsista do CNPq.

${ }^{3}$ Engenharia de Alimentos da Fear/UPF. Bolsista Pibic/CNPq.

${ }^{4}$ Engenharia de Alimentos da Fear/UPF.

* A quem a correspondência deve ser enviada. mistura (farinógrafo e mixógrafo), características de extensão (extensógrafo, alveógrafo e consistógrafo), viscosidade (número de queda, viscosímetro RVA) e de produção ou retenção de gás (reofermentógrafo e maturógrafo). Para avaliar as propriedades funcionais da farinha na produção de biscoitos normalmente é empregado o sugar-snap cookie, método no 10-50D, descrito pela American Association of Cereal Chemists [1, 10, 26, 27].

Embora não constitua um alimento básico como o pão, os biscoitos são aceitos e consumidos por pessoas de qualquer idade. Sua longa vida-de-prateleira permite que sejam produzidos em grande quantidade e largamente distribuidos [6, 7]. Biscoito é o produto obtido pelo amassamento e cozimento conveniente de massa preparada com farinhas, amidos, féculas, fermentadas ou não e outras substâncias alimentícias [9]. A farinha de trigo constitui o principal ingrediente das formulações de biscoitos pois fornece a matriz em torno da qual os demais ingredientes são misturados para formar a massa [12]. A farinha para a elaboração de biscoitos deve apresentar taxa de extração entre 70 e $75 \%$, teor de proteínas entre 8 e $11 \%$ e glúten extensivel [19].

De acordo com LABUSCHAGNE, CLAASSEN \& DEVENTER [17], biscoitos de boa qualidade são obtidos a partir da farinha de trigos moles, de baixo teor de proteína bruta, alta taxa de extração de farinha de 
quebra e pequeno tamanho de partículas, sendo dureza a característica mais importante. Para YAMAMOTO et al. [27] o tamanho de partículas é o parâmetro que apresenta melhor correlação com a qualidade funcional de biscoitos tipo semi-duros, seguido de teor de amido danificado.

O emprego de trigo nacional na fabricação de biscoitos pode proporcionar uma redução do uso de aditivos e a obtenção de produtos finais de qualidade [18], pois entre os cultivares recomendados pela pesquisa para o plantio no Estado do Rio Grande do Sul [24], vários apresentam características desejáveis como teor de proteina bruta, dureza do grão e granulometria de farinha, para a produção de biscoitos. Em trabalho realizado por GUTKOSKI \& SILVEIRA [13] foi observado, com base nas propriedades reológicas das amostras de farinhas de trigo analisadas, que os cultivares BRS 176, EMBRAPA 40, PF 940097, BRS 177, BR 23, BRS 120 e BR 35, da safra de 1998/99, poderiam ser utilizados na produção de biscoitos.

Com o presente trabalho objetivou-se estudar amostras de diferentes cultivares de trigo cultivados no Estado do Rio Grande do Sul, da safra de 1999/2000, para a produção de biscoitos tipo semi-duros, realizando a avaliação através do emprego de análises fisicas, químicas, reológicas e funcionais.

\section{2 - MATERIAL E MÉTODOS}

\section{1 - Material}

Amostras de grãos de trigo (Triticum aestivum $\mathrm{L}$ ) dos cultivares BR 23, BRS 120, BRS 49, BRS 177, BRS 119, BRS 176, EMBRAPA 40 e da linhagem PF 940097, da safra agricola de 1999/2000 foram obtidas da EMBRAPA Trigo, localizada em Passo Fundo, RS. A partir de cultivares recomendados pela Comissão Brasileira de Pesquisa de Trigo [24], realizou-se a seleção de oito materiais para a execução do trabalho no Laboratório de Cereais do Centro de Pesquisa em Alimentação da Universidade de Passo Fundo. As amostras foram armazenadas em câmara climatizada até a realização das análises nos grãos de trigo e a moagem para a extração das farinhas. Os demais ingredientes utilizados na formulação dos biscoitos foram adquiridos no comércio local.

\section{2 - Moagem dos trigos}

As amostras foram limpas manualmente, condicionadas para a umidade de $15 \%$ e após 24 horas moídas no moinho de laboratório Chopin, modelo CD1 (Villeneuve-la-Garenne Cedex, França), realizado de acordo com as instruções do manual do fabricante [8].

Foi realizada uma passagem pelos sistemas de quebra e de redução do moinho pesando-se individualmente as frações farinha de quebra, farinha de redução, farelo e farelinho. A extração de farinha representa a porcentagem de farinha em relação ao total dos produtos de moagem.

\section{3 - Análises físicas e químicas dos trigos e das farinhas}

\subsection{1 - Peso de mil grãos (PMG)}

Foi determinado de acordo com a metodologia descrita por Regras de Análise de Sementes [3] através da contagem de 50 grãos em quadruplicada e calculado o peso de mil grãos.

\subsection{2 - Peso do hectolitro (pH)}

$\mathrm{O}$ pH foi determinado em balança Dalle Molle e expresso em $\mathrm{kg} / \mathrm{hL}$, segundo instruções do fabricante do equipamento (Balanças Dalle Molle Ltda, Caxias do Sul, $\mathrm{RS})$, realizado de acordo com a metodologia descrita por Regras de Análise de Sementes [3].

\subsection{3 - Dureza}

A dureza dos grãos de trigo foi determinada segundo o procedimento descrito por KOSMOLAK [15], que mede o tempo (em segundos) de moagem de $4 \mathrm{~g}$ de trigo utilizando o equipamento micro-hardness tester da Brabender (Brabender OHG, Duisburg, Alemanha). Os graus de dureza foram definidos como duro para tempo < 32 segundos; semi-duro para tempos entre 32 e 44 segundos; semi-mole para tempo entre 45 e 62 segundos e mole para tempo > 62 segundos.

\subsection{4 - Composição química}

Os conteúdos de umidade foram determinados de acordo com a metodologia proposta pela AACC [1], método $\mathrm{n}^{\circ} 44-15 \mathrm{~A}$ usando temperatura de $130^{\circ} \mathrm{C}$ e tempo de uma hora. O teor de nitrogênio total dos grãos de trigo e das farinhas foi determinado pelo método no 46-12 da AACC [1] e o teor de proteina bruta obtido pelo uso do fator 5,7. O teor de cinzas foi determinado de acordo com a AACC [1], método no 08-01, usando temperatura de $600^{\circ} \mathrm{C}$ até peso constante. As análises foram realizadas em duplicata.

\subsection{5 - Número de queda}

O número de queda foi determinado através do uso do aparelho Falling Number, modelo 1500 Fungal (Perten Instruments, Suiça) de acordo com o método no $56-81 \mathrm{~B}$ da AACC [1], utilizando sete gramas de farinha, corrigido para $14 \%$ de umidade.

\subsection{6 - Alveografia}

As características viscoelásticas das amostras de farinha de trigo foram determinadas no alveógrafo Chopin, modelo NG (Villeneuve-la-Garenne Cedex, França) utilizando o método no 54-30 da AACC [1]. Os parâmetros obtidos nos alveogramas são tenacidade $(\mathrm{P})$, que mede a sobrepressão máxima exercida na expansão da massa $(\mathrm{mm})$; extensibilidade (L), que mede o comprimento da curva $(\mathrm{mm})$ e energia de deformação da massa ou força geral do glúten (W), que corresponde ao trabalho mecânico necessário para expandir a bolha até a ruptura, expressa em $10^{-4} \mathrm{~J}$.

\subsection{7 - Cor}

A cor das farinhas foi determinada pelo uso do espectrofotômetro de reflectância difusa, modelo 
ColorQuest II Sphere (Hunter Associates Laboratory, Inc., Reston, EUA), com sensor ótico geométrico de esfera. O aparelho foi calibrado com cerâmica, realizando-se a leitura por reflexão e utilizado ângulo de observação de $2^{\circ}$, iluminante principal D75, iluminante secundário flu-branca fria e reflexão especular incluída (RSIN). No sistema Hunter de cor, corrigido pela CIELab, os valores L (luminosidade) flutuam entre zero (preto) e 100 (branco), os valores de a e b (coordenadas de cromaticidade) variam de -a (verde) até +a (vermelho), e -b (azul) até +b (amarelo). As amostras, apresentando opacidade comprovada e granulometria inferior a $250 \mu \mathrm{m}$, foram transferidas para cubetas de quartzo do próprio equipamento, compactadas, colocadas sobre o sensor ótico de $2,54 \mathrm{~mm}$, realizando-se duas repetições para cada amostra e a leitura em duas posições diferentes conforme o manual do aparelho [14].

\section{4 - Formulação de biscoitos tipo semi-duros}

Para a produção de biscoitos as condições foram previamente definidas no Laboratório de Cereais e, após estudos preliminares, adotada como referência a metodologia proposta pela AACC [1], método no 10-50D. A formulação padrão foi elaborada utilizando 225,5g de farinha, $64 \mathrm{~g}$ de gordura hidrogenada Sancreme da Ceval Alimentos S.A., $130 \mathrm{~g}$ de açúcar cristal com granunolometria inferior a $28 \mathrm{mesh}, 2,1 \mathrm{~g}$ de sal, $2,5 \mathrm{~g}$ de bicarbonato de sódio, $32,8 \mathrm{~mL}$ de solução de dextrose contendo 8,9 gramas em $150 \mathrm{~mL}$ de água e $15,5 \mathrm{~mL}$ de água destilada. A quantidade total de farinha e de água utilizada em cada formulação dependeu do teor de umidade da farinha de trigo e do ajuste, conforme Tabela 1 da AACC [1], método no 10-50D.

A massa foi processada em batedeira elétrica Kitchen Aid, modelo K5SS. A gordura hidrogenada, o açúcar, o sal e o bicarbonato de sódio foram misturados por três minutos em baixa velocidade com pausas a cada minuto para raspagem das paredes do recipiente. A seguir, foram adicionadas a solução de dextrose e a água destilada e misturou-se a massa por um minuto na velocidade dois e um minuto na velocidade quatro. Após a adição de toda a farinha, a massa foi misturada por dois minutos na velocidade quatro com pausas a cada 30 segundos para raspagem das paredes do recipiente. Após a mistura, a massa foi dividida em porções, laminada na espessura de $13 \mathrm{~mm}$ e cortada em matriz de aço inoxidável de $60 \mathrm{~mm}$ de diâmetro. Os discos de circunferência uniforme foram pesados e assados a $204^{\circ} \mathrm{C}$ por 12 minutos. Para cada amostra, foram realizadas duas repetições e produzidas seis unidades de biscoitos. Após uma hora, os biscoitos foram novamente pesados, acondicionados em recipientes e fechados hermeticamente.

A repetitividade do teste desenvolvido a partir da formulação padrão do método no 10-50D da AACC [1] para elaboração dos biscoitos foi realizada utilizandose farinha da amostra de trigo do cultivar BR 23 e em cinco experimentos. Os testes de avaliação das amostras de grãos de trigo e das farinhas foram realizados em duplicata de acordo com o procedimento validado no Laboratório de Cereais do Cepa.

\section{5 - Caracterização dos biscoitos tipo semi-duros}

A perda de peso dos biscoitos foi determinada pela variação de peso antes e após o assamento. O diâmetro dos biscoitos foi determinado com régua de escala milimetrada e a espessura com paquímetro. O fator de expansão foi obtido pela razão entre os valores de diâmetro e altura de cinco biscoitos, corrigindo-se pela altitude e pressão barométrica ao nivel do mar, conforme Tabela da AACC [1], método $n^{\circ}$ 10-50D. O volume foi determinado pelo método de deslocamento de sementes de painço e o volume específico calculado pela relação entre o volume do biscoito assado e o seu peso (mL/g). A determinação do volume específico foi realizada 24 horas após a elaboração dos biscoitos, com três repetições.

\section{6 - Delineamento experimental e análise estatística}

O delineamento utilizado foi o completamente casualizado (DCC), onde a amostra de cada trigo foi considerada um tratamento com o número mínimo de duas repetições por resposta estudada.

Para avaliar os resultados das características estudadas das diferentes amostras de cultivares de trigo foi empregado a análise de variância (ANOVA) e verificada a significância dos modelos pelo teste F [25]. Nos modelos significativos, as médias foram comparadas entre si pelo teste de Tukey, a nivel de 5\% de probabilidade de erro.

\section{3 - RESULTADOS E DISCUSSÃO}

\section{1 - Propriedades físicas e químicas dos grãos e das farinhas de trigo}

A Tabela 1 apresenta alguns parâmetros de qualidade de grãos das amostras dos cultivares de trigo analisados. O peso de mil grãos variou entre 33,84 e 49,53 gramas. O cultivar BR 23 foi significativamente superior. O menor peso de mil grãos foi verificado no cultivar BRS 177. O peso de mil grãos permite definir a melhor densidade de sementes no plantio do trigo e também indica qualidade pelo fato de expressar o enchimento de grãos [24] Em relação ao peso do hectolitro observa-se que os valores encontrados foram muito similares entre os cultivares estudados variando de 77,25 a $82,15 \mathrm{~kg} / \mathrm{hL}$. O peso do hectolitro é um critério simples e amplamente utilizado na avaliação da qualidade de trigo. Quanto maior o $\mathrm{pH}$ maior é o percentual de endosperma e, em geral maior o rendimento de farinha. Segundo GUARIENTI [11], um trigo pode ser considerado muito pesado quando apresenta valores entre 80 e $83 \mathrm{~kg} / \mathrm{hL}$ e pesado para valores de 76 a $79 \mathrm{~kg} / \mathrm{hL}$. De acordo com a norma de identidade e qualidade do trigo [5] o pH é utilizado para a classificação em tipos, necessitando no minimo $78 \mathrm{~kg} / \mathrm{hL}$ para ser considerado tipo 1. Dos trigos analisados somente BRS 49, BRS 176 e BRS 177 apresentaram pH abaixo de 78kg/hL, sendo 
esses classificados como tipo 2, com base no peso do hectolitro. O cultivar EMBRAPA 40 foi significativamente superior quanto ao pH. Já BRS 120 e BRS 177 apresentaram os menores valores sendo significativamente inferiores $(p \leq 0,05)$.

A dureza pode ser definida como a dificuldade de desintegração do grão quando sobre eles é exercida uma pressão. A designação de trigo duro ou mole é um termo descritivo do grau relativo de dureza física apresentado pelo grão, sendo esta controlada por fatores genéticos [21]. Fatores ambientais como solo, capacidade de retenção de água e época de cultivo também podem interferir na dureza dos grãos [2].

TABELA 1. Determinação do peso de mil grãos (PMG), peso do hectolitro $(\mathrm{PH})$, dureza, proteína bruta e cinzas em grãos dos cultivares de trigo

\begin{tabular}{|c|c|c|c|c|c|}
\hline $\begin{array}{l}\text { Amostra de } \\
\text { trigo }^{1}\end{array}$ & $\begin{array}{l}\text { PMG } \\
\text { (g) }\end{array}$ & $\begin{array}{c}\mathrm{PH} \\
(\mathrm{kg} / \mathrm{hl})\end{array}$ & Dureza & $\begin{array}{l}\text { Proteína bruta } \\
\text { (\% de N x 5,7) }\end{array}$ & $\begin{array}{c}\text { Cinzas } \\
(\% \text { em base seca) }\end{array}$ \\
\hline$\overline{\text { BR } 23}$ & 49,53 a & $78,90 \mathrm{c}$ & Mole & $11,62 \mathrm{~b}$ & $1,54 \mathrm{~cd}$ \\
\hline BRS 49 & $36,11 \mathrm{c}$ & $77,25 \mathrm{c}$ & Mole & $12,17 \mathrm{~b}$ & $1,52 \mathrm{~cd}$ \\
\hline BRS 119 & $37,18 \mathrm{c}$ & $78,90 \mathrm{c}$ & Semi-duro & $14,19 \mathrm{a}$ & $1,75 \mathrm{ab}$ \\
\hline BRS 120 & $37,79 \mathrm{c}$ & $78,15 \mathrm{~d}$ & Mole & $10,59 \mathrm{~d}$ & $1,52 \mathrm{~cd}$ \\
\hline BRS 176 & $44,92 \mathrm{~b}$ & $77,25 \mathrm{c}$ & Mole & $10,57 \mathrm{~d}$ & $1,67 a b c$ \\
\hline BRS 177 & $33,84 \mathrm{~d}$ & $77,93 \mathrm{~d}$ & Mole & $11,62 \mathrm{bc}$ & $1,58 \mathrm{~cd}$ \\
\hline EMBRAPA 40 & $38,42 \mathrm{c}$ & 82,15 a & Semi-duro & $11,25 \mathrm{c}$ & $1,83 \mathrm{a}$ \\
\hline PF 9400097 & $43,50 \mathrm{~b}$ & $81,83 \mathrm{~b}$ & Duro & $11,62 \mathrm{bc}$ & $1,42 \mathrm{~d}$ \\
\hline
\end{tabular}

${ }^{1}$ Para cada coluna, médias seguidas da mesma letra não diferem estatisticamente pelo teste de Tukey a $5 \%$ de probabilidade de erro.

Nos trigos analisados, a dureza variou de duro para o PF 9400097, semi-duro para os cultivares BRS 119 e EMBRAPA 40 e mole para os demais cultivares estudados. A dureza é um dos parâmetros que mais afeta o tempo de condicionamento do grão antes da moagem e influencia no padrão de quebra do endosperma, na facilidade de separação entre endosperma e farelo, no tamanho das partículas da farinha, na liberação da farinha de quebra e no consumo energético durante a moagem [12]. De fato, a dureza é uma caracteristica importante na caracterização de cultivares de trigo para a produção de biscoitos [17]. No presente trabalho, os cultivares de trigo BR 23, BRS 49, BRS 120, BRS 176 e BRS 177 poderiam ser utilizados para a produção de biscoitos com base na determinação de dureza do grão.

O teor de proteina bruta nas amostras de grãos dos cultivares de trigo analisados variou entre 10,57 e $14,19 \%$. O maior teor foi verificado no cultivar BRS 119 , sendo significativamente superior $(\mathrm{p} \leq 0,05)$. O conteúdo de proteínas e de cinzas no grão de trigo aumenta de dentro para fora do grão, e desta forma, seus teores nas farinhas tendem a aumentar à medida que se eleva o grau de extração de moagem [21].

Farinhas de trigo de baixo conteúdo protéico são recomendadas para produtos de panificação não fermentados [16]. Por sua vez, farinhas de trigo duro da espé- cie Triticum aestivum, com conteúdo protéico na faixa de 12 a 15\%, são fundamentalmente utilizadas na elaboração de produtos de panificação [12]. As massas alimentícias são preferivelmente produzidas a partir da farinha de trigo duro (Triticum durum) com $15 \%$ ou mais de proteina bruta [12].

Os resultados de moagem dos trigos e alguns parâmetros de qualidade das farinhas estão apresentados na Tabela 2. A taxa de extração de farinha dos trigos analisados variou entre 61,66 e $68,40 \%$. A moagem experimental, feita em laboratório, utiliza equipamentos que reproduzem, em parte, o processo industrial. A avaliação do potencial de moagem de uma cultivar deve ser executada pela análise conjunta dos percentuais de cinzas, da taxa de extração de farinha e do valor do peso do hectolitro [11]. Deve ser considerado ainda o tipo de equipamento utilizado. No moinho piloto Chopin, o rendimento normal de farinha, com uma passagem pelo conjunto de redução é de 58 a 65\% [8] e, portanto, todas as amostras apresentaram bom rendimento.

A taxa de extração de farinha de quebra apresenta uma relação direta com a qualidade da farinha para a produção de biscoitos [17]. Entre as amostras de trigos analisados, os maiores rendimentos de farinha de quebra foram verificados nos cultivares BRS 120, BRS 49, BRS 176, BRS 177 e BR 23, ou seja, nos de dureza mole. O menor rendimento de farinha de quebra ocorreu na amostra de trigo da linhagem PF 9400097, classificado como duro (Tabela 1). Os cultivares BRS 119 e EMBRAPA 40, classificados como semi-duros quanto a dureza ( $T a-$ belas 1 e 2) apresentaram igualmente comportamento intermediário quanto a taxa de extração de farinha de quebra. Portanto, no presente trabalho foi observada boa relação entre a taxa de extração de farinha de quebra e a dureza dos grãos de trigo. Observações similares foram realizadas por LABUSCHAGNE, CLAASSEN, DEVENTER [17].

TABELA 2. Farinha de quebra, taxa de extração, proteína bruta, cinzas, força geral do glúten (W) e número de queda das farinhas dos cultivares de trigo

\begin{tabular}{lcccccc}
\hline Amostra trigo $^{1}$ & $\begin{array}{c}\text { Farinha de } \\
\text { quebra (\%) }\end{array}$ & $\begin{array}{c}\text { Taxa de } \\
\text { extração }(\%)\end{array}$ & $\begin{array}{c}\text { Proteína bruta } \\
(\% \text { de N x 5,7) }\end{array}$ & $\begin{array}{c}\text { Cinzas } \\
(\% \text { base seca })\end{array}$ & $\begin{array}{c}\mathrm{W} \\
\left(10^{-4} \mathrm{~J}\right)\end{array}$ & $\begin{array}{c}\text { Número de } \\
\text { queda (s) }\end{array}$ \\
\hline BR 23 & 34,24 & 62,92 & $10,12 \mathrm{~d}$ & $0,45 \mathrm{~d}$ & 102,48 & $385 \mathrm{~d}$ \\
BRS 49 & 41,15 & 63,99 & $10,72 \mathrm{c}$ & $0,53 \mathrm{c}$ & 249,04 & $301 \mathrm{f}$ \\
BRS 119 & 29,65 & 62,37 & $12,45 \mathrm{a}$ & $0,57 \mathrm{~b}$ & 184,88 & $384 \mathrm{~d}$ \\
BRS 120 & 42,84 & 68,40 & $9,10 \mathrm{f}$ & $0,52 \mathrm{c}$ & 120,4 & $487 \mathrm{~b}$ \\
BRS 176 & 37,37 & 65,87 & $9,11 \mathrm{f}$ & $0,53 \mathrm{c}$ & 146,95 & $450 \mathrm{c}$ \\
BRS 177 & 37,32 & 66,95 & $9,80 \mathrm{e}$ & $0,46 \mathrm{~d}$ & 218,76 & $378 \mathrm{~d}$ \\
EMBRAPA 40 & 34,02 & 65,48 & $9,77 \mathrm{e}$ & $0,54 \mathrm{bc}$ & 135,57 & $322 \mathrm{c}$ \\
PF 9400097 & 23,71 & 61,66 & $11,53 \mathrm{~b}$ & $0,63 \mathrm{a}$ & 134,85 & $500 \mathrm{a}$
\end{tabular}

${ }^{1}$ Para cada coluna, médias seguidas da mesma letra não diferem estatisticamente pelo teste de Tukey a $5 \%$ de probabilidade de erro.

A farinha apresenta uma redução no seu teor de proteína bruta quando comparado com o conteúdo de pro- 
teínas no grão [21]. A redução encontrada no presente trabalho foi de $1,53 \%$, em média. Os menores teores de proteina bruta foram observados nas farinhas de trigo dos cultivares BRS 120 e BRS 176, sendo significativamente inferiores quando comparados com os demais tratamentos.

O conteúdo de cinzas da farinha de trigo é considerado uma importante medida de qualidade. O teor de cinzas da farinha por si só não está relacionado com a qualidade final do produto, mas fornece indicações sobre o grau de extração. Na Legislação Brasileira, o teor de cinzas é usado para classificar a farinha de uso doméstico entre especial, comum e integral. Para a farinha ser classificada como especial, o teor de cinzas deve ser inferior a $0,65 \%$ (expressos em base seca) [4]. De acordo com os dados da Tabela 2, o teor de cinzas das farinhas, expressos em base seca, variou entre 0,45 e $0,63 \%$. O maior teor foi verificado na linhagem $\mathrm{PF}$ 9400097, sendo estatisticamente superior quando comparado com os demais cultivares estudados. Farinhas com altos teores de cinzas têm normalmente coloração mais escura, podendo-se presumir que contenham maiores quantidades de partículas finas de farelo e da porção adjacente ao farelo [12].

A força geral do glúten (W) variou entre 102 e $249 \times 10^{-4} \mathrm{~J}$ (Tabela 2). Os menores valores de $\mathrm{W}$ foram verificados nas amostras de farinhas dos cultivares BR 23 e BRS 120. As amostras dos cultivares de trigo BRS 49, BRS 119 e BRS 177 não apresentaram força geral do glúten típica para biscoitos, pois os valores de $\mathrm{W}$ foram acima de $150 \times 10^{-4} \mathrm{~J}$ [24].

A determinação do número de queda em trigo tem por finalidade verificar a atividade das enzimas amiloliticas no grão, avaliando o grau de germinação na espiga [20]. Para biscoitos, é sugerido que o número de queda seja superior a 150 segundos [24]. Neste trabalho, em todos os cultivares os valores ficaram acima do mínimo sugerido por RASPER [23]. Provavelmente os teores de atividade amilolitica encontrados não devem interferir na qualidade dos biscoitos produzidos. O menor número de queda foi observado no cultivar BRS 49, sendo estatisticamente inferior aos demais materiais estudados.

\section{2 - Propriedades físicas dos biscoitos}

Os resultados dos experimentos de avaliação do método de elaboração de biscoitos utilizando a farinha de trigo do cultivar BR 23 são apresentados na Tabela 3. As características de rendimento, com base no peso dos biscoitos antes e após o forno, volume específico, diâmetro, espessura e fator de expansão avaliados em cinco ensaios não variaram significativamente $(\mathrm{p}<0,05)$ entre si, mostrando boa repetibilidade do método. A metodologia empregada foi utilizada por vários pesquisadores [10, 26, 27] para avaliar a qualidade funcional de farinhas na produção de biscoitos tipo semi-duros.

Na Tabela 4, são apresentados os resultados de cor, avaliada de forma objetiva pelo espectrofotômetro Hunter Lab. Embora para os valores da dimensão vermelho- verde (a) e da dimensão amarelo-azul (b) tenha ocorrido variação significativa entre os tratamentos $(p \leq 0,05)$, em luminosidade (L), observa-se que os resultados não variaram significativamente entre si $(p>0,05)$. A variação significativa de cor dos biscoitos nas dimensões vermelho-verde e amarelo-azul pode ser devido a provável influência do tempo de assamento, associado a sensibilidade do equipamento utilizado para a realização dos ensaios de cor.

TABELA 3. Características físicas dos biscoitos tipo semiduros elaborados com farinha de trigo do cultivar BR 23

\begin{tabular}{lcccccc}
\hline $\begin{array}{l}\text { Dia do } \\
\text { Experimento }^{1}\end{array}$ & $\begin{array}{c}\text { Peso antes } \\
\text { do forno }(\mathrm{g})\end{array}$ & $\begin{array}{c}\text { Peso após } \\
\text { forno }(\mathrm{g})\end{array}$ & $\begin{array}{c}\text { Vol. específico } \\
\left(\mathrm{cm}^{3} \cdot \mathrm{g}^{-1}\right)\end{array}$ & $\begin{array}{c}\text { Diâmetro } \\
(\mathrm{mm})\end{array}$ & $\begin{array}{c}\text { Espessura } \\
(\mathrm{mm})\end{array}$ & $\begin{array}{c}\text { Fator de } \\
\text { expansão }\end{array}$ \\
\hline 1 & $30,75 \mathrm{a}$ & $27,65 \mathrm{a}$ & $1,96 \mathrm{a}$ & $88,33 \mathrm{a}$ & $9,13 \mathrm{a}$ & $9,66 \mathrm{a}$ \\
2 & $29,54 \mathrm{a}$ & $26,67 \mathrm{a}$ & $1,97 \mathrm{a}$ & $87,77 \mathrm{a}$ & $8,93 \mathrm{a}$ & $9,82 \mathrm{a}$ \\
3 & $29,60 \mathrm{a}$ & $26,86 \mathrm{a}$ & $1,89 \mathrm{a}$ & $87,47 \mathrm{a}$ & $8,96 \mathrm{a}$ & $9,75 \mathrm{a}$ \\
4 & $29,58 \mathrm{a}$ & $26,81 \mathrm{a}$ & $1,93 \mathrm{a}$ & $86,47 \mathrm{a}$ & $9,06 \mathrm{a}$ & $9,53 \mathrm{a}$ \\
5 & $28,79 \mathrm{a}$ & $26,16 \mathrm{a}$ & $1,98 \mathrm{a}$ & $86,56 \mathrm{a}$ & $9,13 \mathrm{a}$ & $9,47 \mathrm{a}$ \\
\hline Média & 29,65 & 26,83 & 1,95 & 86,78 & 9,04 & 9,65 \\
\hline C.V. $(\%)$ & 2,53 & 2,49 & 6,87 & 0,85 & 1,17 & 1,47 \\
\hline
\end{tabular}

${ }^{1}$ Para cada coluna, médias seguidas da mesma letra não diferem estatisticamente pelo teste de Tukey a $5 \%$ de probabilidade de erro.

A análise conjunta dos resultados das Tabelas 3 e 4 mostra que a metodologia empregada no Laboratório de Cereais do Cepa, baseada no método 10-50D da AACC [1] para a produção de biscoitos tipo semi-duros é adequada, permitindo a realização do estudo comparativo entre as amostras dos cultivares de trigo selecionados.

TABELA 4. Determinação de cor pelo sistema CIELab dos biscoitos tipo semi-duros elaborados com farinha de trigo do cultivar BR 23

\begin{tabular}{lccc}
\hline Dia do experimento $^{1}$ & L (luminosidade) & $\mathrm{a}^{+}$(vermelho) & $\mathrm{b}^{+}$(amarelo) \\
\hline 1 & $74,71^{\text {al }}$ & $1,90 \mathrm{ab}$ & $29,46 \mathrm{ab}$ \\
2 & $73,79 \mathrm{a}$ & $3,11 \mathrm{a}$ & $31,60 \mathrm{ab}$ \\
3 & $75,43 \mathrm{a}$ & $0,97 \mathrm{~b}$ & $29,07 \mathrm{ab}$ \\
4 & $75,06 \mathrm{a}$ & $1,65 \mathrm{ab}$ & $28,50 \mathrm{~b}$ \\
5 & $75,15 \mathrm{a}$ & $2,64 \mathrm{ab}$ & $29,38 \mathrm{ab}$ \\
\hline Média & 74,83 & 2,05 & 29,60 \\
\hline C.V. $(\%)$ & 1,28 & 35,82 & 3,52 \\
\hline
\end{tabular}

${ }^{1}$ Para cada coluna, médias seguidas da mesma letra não diferem estatisticamente pelo teste de Tukey a $5 \%$ de probabilidade de erro.

$\mathrm{Na}$ Tabela 5 estão apresentados os resultados das características físicas dos biscoitos semi-duros elaborados com farinhas dos cultivares de trigo analisados. O peso dos biscoitos antes do assamento variou significativamente $(\mathrm{p} \leq 0,05)$, sendo observado maior peso nos cultivares BRS 119, BRS 120, BRS 176. Porém, o peso dos biscoitos após o assamento não apresentou diferenças significativas entre as amostras analisadas. A 
variação de peso dos biscoitos antes do assamento devese provavelmente às diferenças na capacidade de absorção de água pelos constituintes da farinha como proteínas, amido danificado e pentosanas.

O volume específico é afetado por vários fatores como a qualidade dos ingredientes usados na formulação da massa, especialmente a farinha e os tratamentos usados durante o processamento [12]. Neste trabalho não houve diferença significativa entre o volume especifico dos biscoitos elaborados com farinhas dos diferentes cultivares de trigo.

TABELA 5. Determinação de características físicas dos biscoitos tipo semi-duros elaborados com farinhas dos cultivares de trigo

\begin{tabular}{lcccccc}
\hline $\begin{array}{l}\text { Amostra de } \\
\text { trigo }^{1}\end{array}$ & $\begin{array}{c}\text { Peso antes } \\
\text { do forno }(\mathrm{g})\end{array}$ & $\begin{array}{c}\text { Peso após } \\
\text { forno }(\mathrm{g})\end{array}$ & $\begin{array}{c}\text { Vol. específico } \\
\left(\mathrm{cm}^{3} \cdot \mathrm{g}^{-1}\right)\end{array}$ & $\begin{array}{c}\text { Diâmetro } \\
(\mathrm{mm})\end{array}$ & $\begin{array}{c}\text { Espessura } \\
(\mathrm{mm})\end{array}$ & $\begin{array}{c}\text { Fator de } \\
\text { expansão }\end{array}$ \\
\hline BR 23 & $29,54 \mathrm{ab}$ & $26,67 \mathrm{a}$ & $1,97 \mathrm{a}$ & $87,77 \mathrm{ab}$ & $8,93 \mathrm{~d}$ & $9,82 \mathrm{a}$ \\
BRS 49 & $28,05 \mathrm{~b}$ & $25,38 \mathrm{a}$ & $2,03 \mathrm{a}$ & $83,90 \mathrm{~cd}$ & $9,27 \mathrm{c}$ & $9,05 \mathrm{bc}$ \\
BRS 119 & $29,17 \mathrm{a}$ & $26,18 \mathrm{a}$ & $2,10 \mathrm{a}$ & $82,76 \mathrm{~d}$ & $9,60 \mathrm{~b}$ & $8,71 \mathrm{c}$ \\
BRS 120 & $30,14 \mathrm{a}$ & $26,48 \mathrm{a}$ & $2,21 \mathrm{a}$ & $88,10 \mathrm{a}$ & $9,13 \mathrm{~cd}$ & $9,64 \mathrm{a}$ \\
BRS 176 & $30,25 \mathrm{a}$ & $26,45 \mathrm{a}$ & $2,11 \mathrm{a}$ & $87,56 \mathrm{ab}$ & $9,07 \mathrm{~cd}$ & $9,65 \mathrm{a}$ \\
BRS 177 & $30,03 \mathrm{a}$ & $26,55 \mathrm{a}$ & $2,33 \mathrm{a}$ & $85,43 \mathrm{bc}$ & $9,76 \mathrm{~b}$ & $8,74 \mathrm{bc}$ \\
EMBRAPA 40 & $28,04 \mathrm{ab}$ & $25,31 \mathrm{a}$ & $2,07 \mathrm{a}$ & $84,70 \mathrm{~cd}$ & $9,27 \mathrm{c}$ & $9,14 \mathrm{~b}$ \\
PF 940097 & $28,89 \mathrm{ab}$ & $25,98 \mathrm{a}$ & $2,10 \mathrm{a}$ & $77,76 \mathrm{e}$ & $10,20 \mathrm{a}$ & $7,62 \mathrm{~d}$
\end{tabular}

${ }^{1}$ Para cada coluna, médias seguidas da mesma letra não diferem estatisticamente pelo teste de Tukey a $5 \%$ de probabilidade de erro.

Os principais critérios na avaliação de farinhas de trigo para a produção de biscoitos são o diâmetro, a espessura e as características superficiais dos biscoitos [16]. Geralmente o maior diâmetro dos biscoitos está associado a trigos de dureza mole, de baixo teor de proteinas e que produzem farinha de quebra em maior quantidade e com pequeno tamanho de partículas. Para YAMAMOTO et al. [27], o fator de expansão prediz melhor a qualidade de uso final da farinha de trigo para a produção de biscoitos.

O diâmetro, a espessura e o fator de expansão dos biscoitos elaborados com amostras de farinhas de diferentes cultivares de trigo variaram significativamente entre si $(\mathrm{p} \leq 0,05)$. O cultivar BRS 120 apresentou o maior diâmetro sem diferir estatisticamente de BR 23 e BRS 176. Nestes mesmos cultivares foram verificados as menores espessuras de biscoitos e os maiores fatores de expansão. O menor diâmetro, a maior espessura e o menor fator de expansão foi observado na linhagem PF 940097.

O diâmetro dos biscoitos variou entre 77,76 e $88,10 \mathrm{~mm}$, a espessura entre 8,93 e $10,20 \mathrm{~mm}$ e o fator de expansão entre 7,62 e 9,82 (Tabela 5). Estes resultados estão de acordo com os dados obtidos no trabalho de YAMAMOTO et al. [27], ressaltando que os valores de fator de expansão estão levemente inferiores provavelmente devido à variação na qualidade das farinhas utilizadas.
YAMAMOTO et al. [27] não encontraram correlação significativa entre o diâmetro dos biscoitos tipo semiduros e o teor de proteína bruta. A ausência de correlação foi justificada devido à pequena variação no teor de proteínas das farinhas estudadas. As análises de correlação dos dados obtidos permitiram ainda que os autores recomendassem o emprego da alveografia como forma de predizer o uso final de farinhas para a produção de biscoitos.

Os resultados das análises de luminosidade (L), dimensão vermelho-verde (a) e dimensão amarelo-azul (b) foram similares entre as amostras estudadas (Tabela 6).

TABELA 6. Determinação de cor pelo sistema CIELab dos biscoitos tipo semi-duros elaborados com farinhas dos cultivares de trigo

\begin{tabular}{lccc}
\hline Amostra de trigo & L (luminosidade) & $\mathrm{a}^{+}$(vermelho) & $\mathrm{b}^{+}$(amarelo) \\
\hline BR 23 & $74,47 \mathrm{a}^{1}$ & $4,04 \mathrm{a}$ & $30,49 \mathrm{a}$ \\
BRS 49 & $69,97 \mathrm{a}$ & $4,02 \mathrm{a}$ & $29,61 \mathrm{a}$ \\
BR 119 & $68,29 \mathrm{a}$ & $7,98 \mathrm{a}$ & $33,42 \mathrm{a}$ \\
BRS 120 & $66,56 \mathrm{a}$ & $8,10 \mathrm{a}$ & $33,11 \mathrm{a}$ \\
BRS 176 & $70,44 \mathrm{a}$ & $6,34 \mathrm{a}$ & $34,10 \mathrm{a}$ \\
BRS 177 & $65,94 \mathrm{a}$ & $9,26 \mathrm{a}$ & $33,49 \mathrm{a}$ \\
EMBRAPA 40 & $72,65 \mathrm{a}$ & $4,24 \mathrm{a}$ & $31,38 \mathrm{a}$ \\
PF 940097 & $69,05 \mathrm{a}$ & $7,11 \mathrm{a}$ & $32,90 \mathrm{a}$
\end{tabular}

${ }^{1}$ Para cada coluna, médias seguidas da mesma letra não diferem estatisticamente pelo teste de Tukey a $5 \%$ de probabilidade de erro.

Embora não significativa, a luminosidade dos biscoitos elaborados com farinha de trigo do cultivar BR 23 foi maior quando comparada aos demais cultivares, atribuido ao fato deste cultivar originar uma farinha clara, desejável para a elaboração de alguns tipos de produtos de panificação.

\section{4 - CONCLUSÕES}

A análise dos resultados do presente trabalho permite concluir que a metodologia utilizada no laboratório para a elaboração de biscoitos tipo semi-duros é adequada para a avaliação de uso final de farinhas a partir de características funcionais. Com base nas propriedades funcionais, as farinhas dos cultivares de trigo BR 23, BRS 120 e BRS 176 são dentre as estudadas, as mais recomendadas para a produção de biscoitos.

\section{5 - REFERÊNCIAS BIBLIOGRÁFICAS}

[1] AACC - AMERICAN ASSOCIATION OF CEREAL CHEMISTS. Approved methods. 9. ed., Saint Paul: AACC, 1995.

[2] ANJUM, F.M.; WALKER, C.E. Review on the significance of starch and protein to wheat kernel hardness. Journal of Science and Food Agriculture, v.56, p.1-13, 1991.

[3] BRASIL. Ministério da Agricultura e Reforma Agrária. Secretaria Nacional de Defesa Agropecuária. Regras 
para Análise de Sementes. Brasília, 1992. 365 p.

[4]BRASIL. Ministério da Saúde. Secretaria de Vigilância Sanitária. Portaria n. 354 de 18 de julho de 1996. Diário Oficial [República Federativa do Brasil], Brasília, 22 de julho de 1996. p. 13557.

[5]BRASIL. Ministério da Agricultura. Instrução Normativa n. 1 de 27 de janeiro de 1999. Diário Oficial [República Federativa do Brasil], Brasília, 29 de janeiro de 1999. p. 132.

[6]BRUNO, M.E.C.; CAMARGO, C.R.O. Enzimas proteolíticas no processamento de biscoitos e pães. Boletim SBCTA, v.29, n.2, p.170-178, 1995.

[7]CHEVAllieR, S.; COLONNA, P.; DELlA VALlE, G.; LOURDIN, D. Contribuition of major ingredients during baking of biscuit dough systems. Journal of Cereal Science, v.31, p.241-252, 2000.

[8]CHOPIN. Instruction Manual Laboratory Mill CD1. Villeneuve-la-Garenne: Chopin, 1998. 16p.

[9]CNNPA- COMISSÃO NACIONAL DE NORMAS E PADRÕES PARA ALIMENTOS. Resolução número 12 de 1978- alimentos e bebidas: padrões de identidade e qualidade. In: Compêndio de Resoluções do CNNPA. São Paulo: Associação Brasileira das Indústrias da Alimentação, 1978. 281p.

[10]DONELSON, J.R.; GAINES, C.S. Starch-water relationships in the sugar-snap cookie dough system. Cereal Chemistry, v.75, n.5, p.606-664, 1998.

[11]GUARIENTI, E.M. Qualidade Industrial de Trigo. 2.ed., Passo Fundo: EMBRAPA-CNPT, 1996. 27p.

[12]EL DASH, A.A.; CAMARGO C.R.O. Fundamentos da Tecnologia de Panificação. São Paulo: Secretaria da Indústria, Comércio e Tecnologia, 1982. 400p.

[13]GUTKOSKI, L.C.; SILVEIRA, L. Avaliação reológica de cultivares de trigo para a produção de biscoitos. XVIII Reunião Nacional de Pesquisa de Trigo, Passo Fundo, RS, 25 a 28 de outubro de 1999. p.386-390.

[14]HUNTERLAB. User's manual with Universal Software Versions 3.5. Reston: HunterLab, 1998 (paginação irregular).

[15]KOSMOLAC, F.G. Grinding time- a screening test for kernal hardness in wheat. Canadian Journal of Plant Science, v.58, p.415-420, Áustria, 1982.

[16]KULP, K.; OLEWNIK, M.C. Functionality of protein components of soft wheat flou in cookie applications. In: PHillips, R.D.; Finley, J.W. (Ed). Protein Quality and the Effects of Processing. New York:
Food Science and Technology, 1989, p.371-388.

[17]LABUSCHAGNE, M.T.; CLAASSEN, A.; DEVENTER, C.S. Biscuit-making quality of backcross derivatives of wheat differing in kernel hardness. Euphytica,v.96, p.263-266, 1997.

[18]MACHADO, L.M.S.; BELÉIA, A.D.P.; SCHOLZ, M.B. Variações de peso e avaliações sensoriais de biscoitos tipo cream crackers produzidos com diferentes farinhas de trigo comerciais. XVIII Reunião Nacional de Pesquisa de Trigo, Passo Fundo, RS, 25 a 28 de outubro de 1999. p.445-450.

[19]MORETTO, E.; FETT, R. Processamento e Análise de Biscoitos. São Paulo: Varela, 1999.

[20]PERTEN, H. Factors influencing falling number values. Cereal Science Today, v.12, n.12, p.516-519, 1967.

[21]POMERANZ, Y. Modern Cereal Science and Technology. New York: VHC Publishers, 1987. 486p.

[22]RAO G.V.; RAO P.H. Methods for determining rheological characteristics of doughs: a critical evaluation. Journal of Food Science Technology, v.30, n.2, p.77-87, 1993.

[23]RASPER, V.F. Quality evaluation of cereal and cereal products. In: LORENZ, K.J \& KULP, K. ed. Handbook of Cereal Science and Technology, New York: Marcel Dekker, 1991. p 595-638.

[24]RECOMENDAÇÃO DA COMISSÃO SUL-BRASILEIRA DE PESQUISA DE TRIGO. Reunião da Comissão Sul-Brasileira de Pesquisa de Trigo. Cruz Alta: Fundacep, 2000. 90p.

[25]SAS- SATATISTICAL ANALYSIS SYSTEM. User's guide: satatistics. 5 ed. Cary, 1985. 956p.

[26]SILVA, M.R.; SILVA, M.A.A.P.; CHANG, Y.K. Utilização da farinha de Jatobá (Hymenaea stigonocarpa Mart) na elaboração de biscoitos tipo cookie e avaliação de aceitação por testes sensoriais afetivos univariados e multivariados. Ciênc. Tecnol. Aliment., v. 18, n. 1, p. 25-34, 1998.

[27]YAMAMOTO, H.; WORTHIGTON, S.T.; HOU, G.; NG, P.K.W. Rheological properties and baking qualities of selecteted soft wheats grown in the United States. Cereal Chemistry, v.73, n.2, p.215-221, 1996.

\section{6 - AGRADECIMENTOS}

Os autores agradecem à FAPERGS pelo auxilio financeiro; aos pesquisadores Pedro L. Scheeren e Martha Z. Miranda da EMBRAPA Trigo pelas contribuições na execução do trabalho. 